Illinois State University

ISU ReD: Research and eData

Theses and Dissertations

4-17-2017

\title{
The Effects of Dietary Intake on Fuel Metabolism during Aerobic Capacity Exercise
}

Taylor Lynn Stephenson

Illinois State University, tlsteph@ilstu.edu

Follow this and additional works at: https://ir.library.illinoisstate.edu/etd

Part of the Human and Clinical Nutrition Commons, and the Kinesiology Commons

\section{Recommended Citation}

Stephenson, Taylor Lynn, "The Effects of Dietary Intake on Fuel Metabolism during Aerobic Capacity Exercise" (2017). Theses and Dissertations. 777.

https://ir.library.illinoisstate.edu/etd/777

This Thesis is brought to you for free and open access by ISU ReD: Research and eData. It has been accepted for inclusion in Theses and Dissertations by an authorized administrator of ISU ReD: Research and eData. For more information, please contact ISUReD@ilstu.edu. 


\title{
THE EFFECTS OF DIETARY INTAKE ON FUEL METABOLISM DURING AEROBIC
}

\section{CAPACITY EXERCISE}

\author{
Taylor Lynn Stephenson
}

\section{Pages}

In order to produce mechanical energy through muscular activity, the body must oxidize carbohydrate, fat, or protein through metabolic processes. The oxidation of these substrates results in the production of ATP, which is then used to produce mechanical energy through exercise. Total body metabolism, specifically metabolism in skeletal muscle depends on factors such as the intensity and duration of exercise, substrate availability, and training status. During exercise at low intensities $\left(25 \%\right.$ of $\left.\mathrm{VO}_{2 \mathrm{max}}\right)$ fat is the primary macronutrient that is oxidized for energy. As the exercise intensity progresses, $\left(65 \%\right.$ of $\left.\mathrm{VO}_{2 \mathrm{max}}\right)$ there is an alteration in skeletal muscle utilization, which results in mainly the use of carbohydrate as an energy source. Intramuscular stores of carbohydrate and fat via muscle glycogen and muscle triglyceride are favorable at high intensity exercise, muscle glycogen more so than intramuscular triglyceride $\left(85 \%\right.$ of $\left.\mathrm{VO}_{2 \max }\right)$. Although many studies have found these results to be true in aerobic athletes, there is limited research on how high intensity exercise effects fuel metabolism in anaerobic trained individuals. PURPOSE: The purpose of this study was to examine how long-term dietary intake effects fuel metabolism during maximal capacity aerobic exercise in resistance trained individuals. METHODS: Eight resistance-trained individuals volunteered to participate. Subjects completed a 5-day food $\log (3$ weekdays, 2 weekend days that represented 5 days of the consistent diet they had been following for $\geq 4$ weeks). Once subjects completed their food $\log$, 
macronutrient intake was averaged over the 5 days. Based off their average percent $\mathrm{CHO}$ intake subjects were placed into either a high carbohydrate $(\mathrm{CHO})(>47 \%)$ group or low $\mathrm{CHO}(<47 \%)$ group. Subjects then completed one continuous aerobic capacity treadmill test. Data was recorded through indirect calorimetry measuring $\mathrm{VO}_{2}, \mathrm{VCO}_{2}$, and calculating respiratory exchange ratio (RER/RQ). Heart rate, rating of perceived exertion (RPE), and $\mathrm{VO}_{2 \max }$ were also recorded. All data was recorded by the VMAX system and compiled for each subject. Subjects that did not met inclusion criteria or did not reach $\mathrm{VO}_{2 \max }$ during the aerobic capacity test were excluded from the study. Data was summarized for $\mathrm{VO}_{2 \max }, \% \mathrm{VO}_{2 \max }, \mathrm{RQ}$, percent calories (\%kcals) of $\mathrm{CHO}$ and fat. The data was then compared between groups to identify if there was a difference in carbohydrate and fat oxidation between groups based off their dietary intake. RESULTS: The high CHO group had the greatest overall RQ at $100 \% \mathrm{VO}_{2 \max }$, and there was no significant difference in RQ between groups at each percent of $\mathrm{VO}_{2 \max }$. Overall, the low $\mathrm{CHO}$ group had a greater \% kcal of $\mathrm{CHO}$, while the high $\mathrm{CHO}$ group had a greater $\% \mathrm{kcals}$ of fat during the aerobic capacity test. There was no significant difference between \%kcal of fat and CHO between groups. CONCLUSION: Overall, moderate changes in dietary intake do not significantly affect carbohydrate and fat utilization in resistance trained individuals during maximal aerobic capacity exercise.

KEYWORDS: Aerobic capacity, Carbohydrate, Fuel metabolism, Nutrition 


\section{THE EFFECTS OF DIETARY INTAKE ON FUEL METABOLISM DURING AEROBIC}

CAPACITY EXERCISE

\section{TAYLOR LYNN STEPHENSON}

A Thesis Submitted in Partial Fulfillment of the Requirements for the Degree of

\section{MASTER OF SCIENCE}

School of Kinesiology and Recreation

\section{ILLINOIS STATE UNIVERSITY}


Copyright 2017 Taylor Lynn Stephenson 


\section{THE EFFECTS OF DIETARY INTAKE ON FUEL METABOLISM DURING AEROBIC CAPACITY EXERCISE}

\section{TAYLOR LYNN STEPHENSON}

COMMITTEE MEMBERS:

Dale D. Brown, Chair

Jennifer L. Barnes

Kelly R. Laurson

Daniel Dodd 


\section{ACKNOWLEDGMENTS}

Foremost, I would like to express my gratitude to my committee members, Dr. Dale Brown, Dr. Kelly Laurson, Dr. Daniel Dodd, and Dr. Jennifer Barnes for their continual guidance and advice throughout the process of research and writing for this thesis. I would especially like to thank my thesis chair, Dr. Dale Brown for his persistent support that encouraged me to go in the direction of researching and writing. Also, for his advisement and knowledge that helped me throughout my research and time at Illinois State University. I would also like to thank Nate Fillers, an exercise physiology lab graduate assistant, who helped me collect data for use in this study. Lastly, I would like to thank my family: my parents, Rob and Michelle Stephenson, my brothers, Ryan and Parker Stephenson, my boyfriend, Brendon Buff, and numerous close friends for their constant support and love.

T. L. S. 


\section{CONTENTS}

\section{Page}

ACKNOWLEDGMENTS

CONTENTS

TABLES

iii

FIGURES

iv

CHAPTER

I. THE EFFECTS OF DIETARY INTAKE ON FUEL METABOLISM DURING AEROBIC CAPACITY EXERCISE

Introduction

Methods

Subjects

Diet Analysis

Experimental Design

Statistical Analysis

Results

Discussion

Conclusion

References

II. EXTENDED REVIEW OF THE LITERATURE 21

Specific Research

Fuel Metabolism during Various Intensity Exercise

The Effects of Dietary Carbohydrate Alterations on

The Effects of Dietary Fat Alterations on Exercise Metabolism

Summary

References 


\section{TABLES}

Table

Page

1. Descriptive statistics of subjects

2. Average macronutrient composition and total calories over five days based on subjects' long term dietary intake between high and low $\mathrm{CHO}$ diet conditions.

3. Correlation between average carbohydrate intake and mean RQ values at each $\% \mathrm{VO}_{2 \max }$ 


\section{FIGURES}

Figure $\quad$ Page

1. A comparison of mean $\mathrm{RQ}$ values at each $\% \mathrm{VO}_{2 \max }$ during the aerobic capacity test between conditions

2. A comparison of mean $\% \mathrm{kcals}$ from $\mathrm{CHO}$ at each $\% \mathrm{VO}_{2 \max }$ during the aerobic capacity test between conditions.

3. A comparison of mean $\%$ kcals from fat at each $\% \mathrm{VO}_{2 \max }$ during the aerobic capacity test between conditions. 


\title{
CHAPTER I
}

THE EFFECTS OF DIETARY INTAKE ON FUEL METABOLISM DURING AEROBIC

\section{CAPACITY EXERCISE}

\author{
Introduction
}

Training and nutrition are two pertinent factors when it comes to improving human performance. Over the past 60 years a review of research clearly shows that optimal athletic performance is promoted by adequate energy intake. Dietary intake before, during, and after exercise affect the energy demands required in order to produce ATP ${ }^{1}$. Research suggests that training intensity may not alter the total amount of energy expended, but rather the amount of energy utilized from carbohydrates and fat ${ }^{2}$. Certain physiological factors determine the use of carbohydrate and fat oxidation. Current literature supports that total body metabolism, specifically skeletal muscle is influenced by training status, intensity and duration of exercise, gene expression/adaption, and substrate availability ${ }^{3}$. Macronutrient guidelines prior, during, and post exercise for optimal athlete performance have been a controversial topic in the sports nutrition industry. There are a variety of guidelines for athletes to follow from sports nutrition books, research articles, and credible organizations like ACSM and NSCA, but each of these sources offer different macronutrient guidelines and macronutrient timing options for different types of athletes to improve performance and maintain lean mass. While there is a variety of accessible information it can be hard to determine, what information is credible and what is not. Therefore, this leads to confusion as to what is the most optimal macronutrient intake for certain athletes prior, during, and after an event. 
It is known that when a mixed diet is consumed (50-65\% carbohydrate, $25-35 \%$ fat, 15 $20 \%$ protein) plasma free fatty acids (FFA) are the main substrate utilized during low intensity exercise ${ }^{1}$. As exercise intensity increases $\left(65-85 \%\right.$ of $\left.\mathrm{VO}_{2 \max }\right)$ there is a progressive decline in FFA concentrations which is offset by an increased reliance on carbohydrate energy. ${ }^{1}$ Specifically, plasma glucose uptake and particularly muscle glycogen utilization are increased during high intensity exercise ${ }^{4}$. Carbohydrate intake tends to have the most prominent effect on substrate metabolism, because muscle favors carbohydrate as an energy source during a majority of exercise based on its availability through endogenous and exogenous sources. In general, an increase in dietary carbohydrate intake results in higher carbohydrate oxidation rates due to an increase in plasma glucose and muscle glycogen. This is especially true when trained individuals are participating in prolonged, moderate intensity exercise. On the contrary, a low carbohydrate intake (5-40\%) and fat rich diets increase fat oxidation rates due to a higher concentrations and availability of plasma free fatty acids (FFA) and intramuscular triglycerides. Consequently, this can result in greater protein oxidation rates, and possibly decrease the rate of protein synthesis. Although, protein metabolism is not seen as a major fuel source, even when carbohydrate intake is low, the possible adverse effects should not be overlooked when the goal is to preserve lean body mass, improve training, and performance.

It is evident in earlier studies that the effects of dietary alterations in carbohydrate and fat effect how chemical energy is metabolized in muscle to produce ATP and use as mechanical energy during exercise. Some of the first recognized studies by Krogh and Lindhard,1920; Christensen \& Hansen $1939 ;{ }^{5,6}$ observed that a reduction in carbohydrate intake resulted in a decreased reliance on carbohydrate energy and increased fat utilization as energy during exercise, while causing a state of ketosis, and adverse effects to endurance capacity. Conversely, 
an increase in carbohydrate intake resulted in elevated carbohydrate oxidation and increased endurance capacity. These findings are generalizable to many studies that have examined the effects of dietary intake on fuel metabolism during endurance capacity exercise.

Once research expanded to various intensities and durations during exercise, findings started to become inconsistent with the generalizations of early research, these studies showed that different intensities and durations of exercise also influence fuel metabolism. Two studies by Pitiladis ${ }^{7,8}$ et al., demonstrated that different carbohydrate compositions ( $70 \%$ high $\mathrm{CHO}$, $40 \%$ low-CHO) had no effect on performance when trained individuals participated in short duration, moderate to high intensity exercise. Both studies suggested there was no difference due to the moderate difference in percentage of $\mathrm{CHO}$ between groups. But there was a significant difference in RER between the high and low $\mathrm{CHO}$ groups, where the low $\mathrm{CHO}$ stimulated an elevated fat oxidation state compared to the high $\mathrm{CHO}$ group. However, multiple studies indicate that increased carbohydrate intake in the days/ weeks preceding a prolonged endurance event resulted in improved performance or no difference in performance compared to those on a mixed diet regimen or high fat diet ${ }^{9,13,14}$. These results present that carbohydrate loading may be more beneficial during endurance running events.

Like carbohydrate oxidation, fat utilization is also influenced by training status, substrate availability, intensity of exercise, and duration. It is known that FFA are predominately utilized at $25 \%$ of $\mathrm{VO}_{2 \max }$, while intramuscular triglycerides are maximally used at $65 \%$ of $\mathrm{VO}_{2 \max }$ during a mixed diet, after a 10-12 hour fasted state. ${ }^{1}$ A review of literature has inconsistent findings on various dietary fat compositions and their effects on fuel metabolism and performance. Numerous studies have found that high fat, low $\mathrm{CHO}$ (ketogenic) diets result in increased fat oxidation as well as an improvement or no difference in performance ${ }^{10-15}$. While other 
investigations reported that high carbohydrate diets either improved or didn't change endurance

performance, compared to high fat diets ${ }^{16,17}$. In humans, it is unclear when exactly adaption to high fat diet at the muscular level occurs. Some studies have seen changes as quick as 7 days, with improved performance, while other studies have reported adaptations to occur after 4-7 weeks, with no change, increased or decreased performance diet modifications ${ }^{10,15,17}$.

Furthermore, previous studies have found that physiological adaptations to high fat diets result in an increase capacity to transport, oxidize and store fat in muscle due to increased carnitine palmitoyl transferase 1 (CPT-1) gene expression ${ }^{3}$.

A majority of research investigates the effects of dietary intake on fuel metabolism in aerobic athletes. It is still unclear how dietary intake may affect performance of anaerobic athletes during increasing intensity aerobic exercise, due to lack of feasibility and research on this topic. Also, more research is needed to determine the duration of physiological adaptions at the muscular level as a result of changes in dietary composition. In humans, it is unclear when adaption to newly introduced diet at the muscular level occurs, since a wide range of studies have investigated both short term and long term dietary interventions. Therefore, the purpose of this study was to investigate the effects of long term dietary intake on fuel metabolism during aerobic capacity exercise in resistance trained males and females.

\section{Methods}

Subjects: 10 resistance trained individuals volunteered to participate in the study (4 females, 6 males). The inclusion criteria were as follows: between the ages 18-35 years, low ACSM risk stratification, resistance trained on $>4$ days per week or ( $\geq 150 \mathrm{~min} /$ week), following a consistent diet (within 5-10\% of macronutrient percentage each day) for greater than or equal 
to 4 weeks (not $>4,000 \mathrm{kcal} / \mathrm{day}$ or $<1,000 \mathrm{kcal} /$ day), and able to perform maximal aerobic activity for no more than 18 minutes. Eligibility was determined with the completion of a preparticipation medical history, physical activity readiness questionnaire, and dietary analysis. Participants that did not meet all requirements, had chronic health or metabolic condition/s, or injuries that inhibited performance were excluded from this study. Nine subjects met the inclusion criteria and one subject did not reach $\mathrm{VO}_{2 \max }$ and another subject did not meet the consistent diet criteria, so these two subjects were excluded. The physical characteristics [mean $(\mathrm{SD})]$ of the eight remaining subjects were: age $26.1( \pm 5.7)$ years; height $68.7( \pm 4.8)$ inches; weight $180.0( \pm 39.2)$ lbs.; $\mathrm{VO}_{2 \max } 49.1( \pm 5.2) \mathrm{ml} / \mathrm{kg}^{-1} / \mathrm{min}^{-1}$. All subjects were informed of the purpose and possible risk associated with participation. This study was approved by the Institutional Review Board of Illinois State University.

Diet analysis: Prior to testing subjects were given a 5-day food log to complete (3 weekdays, 2 weekend days), using MyFitnessPal App or website. The food log represents a 5day period of the diet they were currently participating in for $4+$ weeks. This was used to determine the macronutrient composition (percentage) and total caloric intake used by resistance trained males and females. Participants were encouraged to measure their intake using a food scale, measurement cups, and spoons, or scan food labels using the MyFitnessPal app to ensure the most accurate measurements. Once the food log was completed, macronutrient percentage of carbohydrate, fat, and protein were averaged over the 5 days. Based on their average $\mathrm{CHO}$ intake the eight subjects were then placed into either a high carbohydrate ( $>47 \%$ intake) or low carbohydrate $(<47 \%)$. Between the eight subjects the cut-off point between groups came to $47 \%$ $\mathrm{CHO}$, which was how \% $\mathrm{CHO}$ between the high and low group were determined. 
Experimental Design: The study took place in the Illinois State University exercise physiology lab, where subjects completed one continuous treadmill aerobic capacity test. Participants were required to refrain from heavy exercise (>150 bpm) or any exercise that would induce muscle soreness 24 hours prior to test. They were also told to refrain from consuming alcohol, tobacco, and caffeine 24 hrs. prior to testing, as well as abstaining from consuming a high caloric meal and beverages 3 hours prior to testing, since this could alter an accurate representation of the diet they were currently following due to higher concentrations of dietary substrates in blood plasma. Subjects were told they could consume water and a small snack 1-2 hours prior. Upon arrival subjects filled out an informed consent form. During the progressive test, heart rate (bpm), respiratory exchange ratio $\left(\mathrm{VCO}_{2} / \mathrm{VO}_{2}\right)$, relative and absolute $\mathrm{VO}_{2}$, and rating of perceived exertion (RPE) variables were measured and recorded. Polar ${ }^{\circledR}$ heart rate monitors were worn along with a chest strap to measure heart rate. Indirect calorimetry (Vmax Encore metabolic cart, Becton, Dickson and Company.) was measured to determine breath by breath oxygen consumption $\left(\mathrm{VO}_{2}\right)$ and carbon dioxide production $\left(\mathrm{VCO}_{2}\right)$. The system was calibrated prior to each subject's test to ensure each subject received the most accurate results. Subjects initially started at a $0 \%$ grade and performed a 5-10-minute warm-up at a walking speed of $3.0 \mathrm{mph}$. Once the test began subjects picked a speed between 5.0 and $7.0 \mathrm{mph}$, which was kept constant throughout the entire test. After each 2 minute stage the grade increased by $2.5 \%$. The participant continued to perform the test until volitional exhaustion or these criteria were met: RER of $>1.05$, a plateau in oxygen consumption, heart rate plateau with increasing intensity, or reaching an RPE of $>17$. Once the test was over subjects were encouraged to cool down for 5-10 minutes at a comfortable walking speed. Subjects were excluded from data analysis if they were not able to attain the $\mathrm{VO}_{2}$ max criteria previously described. 
Statistical Analysis: Data from this study was analyzed using IBM SPSS Statistics Version 20 (Armonk, New York) and Microsoft Excel. The results are presented as means \pm SD. Descriptive statistics were used to describe the sample demographics of age, height, weight, and $\mathrm{VO}_{2 \max }$ values (Table 1). Breath by breath data was condensed into average $\mathrm{VO}_{2 \max }$ values starting at $25 \%$ and increasing in $10 \%$ increments up to $95 \%$, as well as their $100 \%$ of $\mathrm{VO}_{2 \max }$ value. $\mathrm{RQ}$ values were then taken from each 10 percent increment of $\mathrm{VO}_{2 \max }$. Descriptive statistics were run to assess the mean differences between groups on average carbohydrate, fat, and protein intake (Table 2). The high and low CHO group means were further assessed and compared between RQ values (Figure 1), \%kcals of $\mathrm{CHO}$ (Figure 2), and \%kcals of fat (Figure 3) at $25-100 \%$ of $\mathrm{VO}_{2 \max }$, and then tested for significance using an independent sample $t$-test. Percent kcals of $\mathrm{CHO}$ and fat were determined by using a table that provided non-protein RQ values, including percentage of kilocalories derived from carbohydrate and fat. ${ }^{18}$

The association between carbohydrate intake and RQ values at $25-100 \%$ of $\mathrm{VO}_{2 \max }$ was also analyzed. A correlation analysis was run to determine the relationship between average carbohydrate intake and $\mathrm{RQ}$ values at $25-100 \%$ of $\mathrm{VO}_{2 \max }$ (Table 3). Statistical significance was set at $\mathrm{P}<0.05$ for all tests.

\section{Results}

The sample of this study included a total of eight subjects consisting of 2 females and 6 males. Overall subjects had a mean age of $26.1 \pm 5.7$ years; height $68.7 \pm 4.8$ inches; weight $180.0 \pm 39.2 \mathrm{lbs}$.; $\mathrm{VO}_{2 \max } 49.1( \pm 5.2) \mathrm{ml} / \mathrm{kg}^{-1} / \mathrm{min}^{-1}$ as presented in Table 1. The mean macronutrient percentage intake for the high $\mathrm{CHO}$ group was $51.3 \pm 5.1 \%$ carbohydrate, $26.6 \pm$ $7.7 \%$ fat, and $22.2 \pm 3.6 \%$ protein; low $\mathrm{CHO}$ group was $42.4 \pm 6.1 \%$ carbohydrate, $30.1 \pm 6.1 \%$ 
fat, and $26.8 \pm 5.6 \%$ protein. The average total caloric intake between groups was higest in the low CHO group (2589 kcals) compares to the high CHO group (2203 kcals) shown in Table 2. The high CHO likely had a lower intake because both females were in the high CHO group, and all males were in the low $\mathrm{CHO}$ group, and all of the males had higher total calories compared to the females.

When comparing the mean RQ values between the high and low CHO groups it was found that, on average, each group had a progressive increase in $\mathrm{RQ}$ as $\% \mathrm{VO}_{2 \max }$ increased. For a majority of the aerobic capacity test both groups were in a carbohydrate oxidation state ( $\geq .90)$, specifically at $\geq 45 \%$ of max. The high $\mathrm{CHO}$ group tended to have a greater mean RQ value compared to the low $\mathrm{CHO}$ group $67 \%$ of the time. The high $\mathrm{CHO}$ group had increased RQ values at $45,65,75,85,95$, and $100 \%$ of $\mathrm{VO}_{2 \max }$. Although, the low $\mathrm{CHO}$ group did have higher mean RQ values at $25 \%$ (low: $0.83 \pm .04$; high: $0.80 \pm .03$ ) and 55\% (low: $0.94 \pm .03$; high: $0.91 \pm .16$ ) of $\mathrm{VO}_{2 \max }$ and equal values at $35 \%$ (low: $0.88 \pm .04$; high: $0.88 \pm .05$ ). The maximum RQ value was obtained in the high $\mathrm{CHO}$ group at $100 \%(1.20 \pm .07)$ of $\mathrm{VO}_{2 \max }$ and the lowest value in the high carb group at $25 \%(.80 \pm .03)$ of $\mathrm{VO}_{2 \max }$. An independent t-test showed that there was no significant difference in mean $\mathrm{RQ}$ values between groups at each percent of $\mathrm{VO}_{2 \max }$. Results are shown in Figure 1.

Figure 2 shows a direct relationship between $\% \mathrm{VO}_{2 \max }$ and $\% \mathrm{kcals}$ of $\mathrm{CHO}$. In both groups, as $\% \mathrm{VO}_{2 \max }$ increased \%kcals of $\mathrm{CHO}$ increased simultaneously. The most drastic difference between groups was shown at $25 \%$ with the high $\mathrm{CHO}$ group at $29.38 \% \mathrm{kcals}$ of $\mathrm{CHO}$ and the low $\mathrm{CHO}$ group at $43.7 \%$. The high $\mathrm{CHO}$ group had great \%kcals of $\mathrm{CHO}$ at 45 and $75 \%$ of max, while the low $\mathrm{CHO}$ group had greater percentages at $25,35,55$, and $65 \%$. Both groups reached $100 \%$ kcals of $\mathrm{CHO}$ by $85 \%$. The high $\mathrm{CHO}$ group reached $100 \%$ kcals of $\mathrm{CHO}$ before 
the low $\mathrm{CHO}$ group at $75 \%$ of max whereas the low $\mathrm{CHO}$ group reached it at $85 \%$ of max. Overall, the low $\mathrm{CHO}$ group tended to burn more kcals of $\mathrm{CHO}$ than the high $\mathrm{CHO}$ group during the majority of the aerobic capacity test. The difference in \%kcals of $\mathrm{CHO}$ was not statistically different between groups. \% Kcals of $\mathrm{CHO}$ is counterbalanced by $\% \mathrm{kcals}$ of fat. There was a direct inverse relationship between $\% \mathrm{VO}_{2 \max }$ and $\% \mathrm{kcals}$ of fat. In the low $\mathrm{CHO}$ group, as $\% \mathrm{VO}_{2 \max }$ increased \%kcals of fat progressively decreased and in the high $\mathrm{CHO}$ group, for the most part there was an overall decrease except for a $10.6 \%$ increase in $\%$ kcals of fat at $75 \%$ of max. The high CHO group had a greater \%kcals of fat at $25(69.0 \%), 55(31.7 \%)$, and 75\% (10.6) of max, while the low $\mathrm{CHO}$ group had greater \%kcals of fat at $45(33.6 \%)$ and $65 \%$ $(1.8 \%)$ of max. Both groups had equal values at $35 \%(41.0 \%)$ of max. Values are shown in Figure 3. Overall, the high $\mathrm{CHO}$ group tended to have a greater \%kcals of fat during the aerobic capacity test compared to the low $\mathrm{CHO}$ group. Like \%kcals of $\mathrm{CHO}$ there was also no significant difference in mean \%kcals of fat between groups at each percent of $\mathrm{VO}_{2 \max }$.

Results of the correlational analysis revealed that there was an inconsistent weak relationship between average $\mathrm{CHO}$ intake and RQ values at each percent of $\mathrm{VO}_{2 \max }$. The moderately strong relationships tended to more toward the moderate to high intensities and the strongest relationship between average carb intake and RQ values was at 100\%. Moderately strong relationships were: 65 (.658), $85(.621), 95(.627)$ and $100(.822) \% \mathrm{VO}_{2 \max }$, with $100 \%$ $\mathrm{VO}_{2 \max }$ being a significant relationship at the alpha level 0.05 . The rest of the percentages not mentioned had a weak relationship and were not significant. These results are shown in Table 3. 


\section{Discussion}

Based on the data collected and analyzed in this study, it is evident that moderate differences in diet composition during aerobic capacity exercise in resistance trained individuals do not significantly affect carbohydrate and fat oxidation. These findings are in agreement with previous studies investigating the effects of dietary intake on fuel metabolism and performance ${ }^{7,14,19}$. A study by Muoio et al. ${ }^{14}$ examined the effects of a high CHO, fat restricted $\operatorname{diet}(73 \% \mathrm{CHO}, 15 \%$ fat, $12 \%$ protein) compared to a moderate $\mathrm{CHO}$ and fat rich diet $(50 \%$ $\mathrm{CHO}, 38 \%$ fat, $12 \%$ protein) on performance, metabolic, and physiological measures in highly trained endurance runners performing high intensity exercise. They also included the subjects overall average normal diet $(61.2 \% \mathrm{CHO}, 24.3 \%$ fat, and $13.7 \%$ protein) and measured performance and metabolic outcomes. Subjects performed a progressive intensity maximal treadmill test, which was repeated for each dietary trial. They found that the high fat group had a higher $\mathrm{VO}_{2 \max }$ compared to the $\mathrm{CHO}$ and normal diet groups, and the $\mathrm{CHO}$ group had the lowest $\mathrm{VO}_{2 \max }$, all were at a significant level, which contrary to our findings in this study on performance measures. Although, they did find that RER was unaffected between groups, and is similar to our results. The authors believe RER was unaffected due to the moderate changes in diet composition between group, and that RER may not be a valid measure to determine substrate utilization especially during heavy exercise.

A previous study by Zajac et al. ${ }^{10}$ assessed the effects of a ketogenic diet on exercise metabolism in off-road cyclist. Subjects followed a mixed $(50 \% \mathrm{CHO}, 30 \%$ fat, and $20 \%$ protein) or a ketogenic diet (15\% $\mathrm{CHO}, 70 \%$ fat, and 15\% protein) while performing 2 days of testing. On day one subjects completed a progressive cycloergometer test to determine $\mathrm{VO}_{2 \max }$ and level of lactate threshold (LT). On the second day subject performed a continuous cycle test 
for a duration of $105 \mathrm{~min}$ at $85 \%$ of LT for the first $90 \mathrm{~min}$ and last $15 \mathrm{~min}$ was set at $115 \%$ for maximum individual intensity. Similar to Muoio et al ${ }^{14}$, they found that $\mathrm{VO}_{2 \max }$ was significantly higher in the ketogenic diet group compared to the mixed diet, but LT workload was significantly decreased in the ketogenic group in comparison to the mixed diet group. The authors suggest the ketogenic diet is beneficial to increase $\mathrm{VO}_{2 \max }$ and performance due to its favorable changes in body composition. The reason being that decreased body mass, specifically fat mass, played a role in increasing performance. Subjects in the ketogenic group had significantly lower body mass which results in less mass to provide chemical energy to working muscle and less work that the subject will have to perform. This may hold true for both studies although body composition was not reported in Muoio's study. In contrast to the present study and Muoio et al ${ }^{14}$, Zajac et al. ${ }^{10}$ reported that RER was significantly lower in the ketogenic diet, throughout the endurance test, although there were no significant differences during maximal effort, which corresponds with the present study's findings. This suggests continuous exercise at $85 \%$ of LT on a ketogenic diet promoted fat oxidation and inhibited carbohydrate oxidation, due to an increased level of FFA concentrations, but when heavy exercise was induced no differences were seen ${ }^{10}$. The studies by Muoio et al ${ }^{14}$ and Zajac et al. ${ }^{10}$ are in agreement with the effects of dietary composition on performance, where high fat diets in accordance with either a low $\mathrm{CHO}$ or moderate $\mathrm{CHO}$ intake are more beneficial for improving performance than a mixed diet, while the present study suggests that a high $\mathrm{CHO}$ intake had a slightly better non-significant performance outcome measures compared to the low $\mathrm{CHO}$ group. The present study and the previous two mentioned are all in agreement that RER is unaffected when performing maximal capacity exercise even when drastic modifications to dietary intake are made. 
When comparing carbohydrate intake on performance there seems to be inconsistent findings, although intensity and duration play a significant role. Simonsen et al. ${ }^{19}$ found that alterations in dietary carbohydrate intake result in different performance outcomes. This study design included rowers that were following a high $(10 \mathrm{~g} / \mathrm{kg})$ or moderate $\mathrm{CHO}$ diet $(5 \mathrm{~g} / \mathrm{kg})$, while assessing muscle glycogen content and power output over a 4-week period. In the morning, subjects trained at $70 \%$ of peak $\mathrm{VO}_{2}$ for 40 minutes and in the evening performed three $2,500 \mathrm{~m}$ rowing time trials to examine power output. Results showed that the high $\mathrm{CHO}$ group significantly increased more muscle glycogen content and had an overall higher mean power output during moderately high intensity exercise. These findings are consistent with those of Williams et al. ${ }^{9}$ which reported that eighteen runners on a high $\mathrm{CHO}$ supplementation resulted in increased performance compared to those on a normal mixed diet regimen, during a $30 \mathrm{~km}$ treadmill time trial. All subjects ran 2 time trials, during the first-time trial all subjects performed on their normal diet. After their first time trial subjects were randomly assigned to 7 days of a control (normal diet) or high CHO diet. During the second-time trial, 6 men participating in the high $\mathrm{CHO}(70 \%)$ group ran faster during the last $5 \mathrm{~km}$ of their time trial compared to trial 1 on their normal diet. Although, there were no overall differences in performance times between groups.

While the previous studies indicate that high $\mathrm{CHO}$ intake resulted in improved performance time and mean power output, they are inconsistent with other studies that investigated the effects of carbohydrate intake on performance. Pitsiladis et al. ${ }^{8}$ reported that moderate changes in dietary carbohydrate had no effect on performance in trained runners during a 10km run. This crossover study had subjects follow a normal CHO diet (55\%) for 7 days, and then groups were randomly assigned to high $\mathrm{CHO}$ (55\% 4 days, and then $70 \%$ for 3 days), or low 
$\mathrm{CHO}(40 \%)$ for 7 days. Subjects then performed a $10 \mathrm{~km}$ trail run at $4 \%$ grade at $80 \%$ of their $\mathrm{VO}_{2 \max }$, and there was no significant difference between dietary conditions. Although, the definition of a "low carb diet" can be misconstrued in this study, subjects in the low $\mathrm{CHO}$ on average consumed $350 \mathrm{~g}$ per day, which is much greater than other studies that use a low $\mathrm{CHO}$ condition or even a normal mixed diet. These results are consistent with Sherman et al. ${ }^{20}$ who also reported that carbohydrate loading did not benefit performance since there were no differences in performance run times, or post-exercise glycogen levels in trained runners during $20.9 \mathrm{~km}$ run. Despite this, our study along with Pitsiladis et al. ${ }^{8}$ methodology didn't include muscle glycogen levels, although we found similar results to these studies that suggest an increased or decreased availability of muscle glycogen has no effect on performance or exercise capacity when consuming a low $\mathrm{CHO}$ or high $\mathrm{CHO}$ diet in running events with a duration of $<90$ minutes in trained individuals ${ }^{8}$. Overall, we believe our findings were not significant between groups due to the moderate changes in dietary intake similar to previous studies.

Our findings do not reflect previous research when it involves substrate availability and its effects on RER. A majority of studies found that when substrates concentrations are higher than others there is an increased reliance for exercising muscle to utilize the substrate that has higher concentrations through endogenous and exogenous sources. For example, individuals participating in a low $\mathrm{CHO}$ or fat diets compared to either a high $\mathrm{CHO}$, or moderate $\mathrm{CHO}$ (mod$\mathrm{CHO}$ ) diet, resulted in decreased $\mathrm{CHO}$ oxidation and increased fat oxidation running at a moderate intensity $6,8,10,21,22$. Although the present study determined that the high $\mathrm{CHO}$ group utilized more \%kcals from fat compared to the low $\mathrm{CHO}$ group, which would disagree with this physiology previously reported. 
This inconsistency between studies is likely due to the fact that the present study had individuals performing at maximal capacity exercise, which as stated previously can alter valid results of RER through indirect calorimetry. The present study also didn't provide extreme dietary conditions as those formerly used in other studies, and was similar to other findings since their dietary conditions only provided moderate changes as well. The subject sample didn't obtain the variance in diet compositions between subjects that the present study was hoping for. With 8 subjects, the cutoff point was $47 \%$ average $\mathrm{CHO}$ intake. Four subjects were below, and four subjects were above that cutoff point. There was a $\leq 15 \%$ variance in average $\mathrm{CHO}$ intake within groups, and overall the lowest $\mathrm{CHO}$ intake was $32.5 \%$ (low $\mathrm{CHO}$ group) and highest CHO intake was $59 \%$ (high $\mathrm{CHO}$ group). We believe this may be one of the main reasons the findings were not significant. Another reason the present study may not have seen significant changes in RER between groups, may be due to short duration stages $(2 \mathrm{~min})$ and overall a shorter session of average exercise time. Previous studies had trained individuals working at high intensities for 30- 120 minutes, which allows metabolic pathways time to adjust to exercise intensity and substrate utilization. It has been mentioned that RER may not be an accurate representation of substrate utilization during heavy exercise. This may be due to a couple of factors. The excess $\mathrm{CO}_{2}$ produced during heavy exercise can come from buffering of lactic acid in the blood, and can produce elevated RQ values of $>1.0$, which may not solely reflect cellular metabolism $^{23}$. This is especially true in individuals that do not normally participate in maximal aerobic exercise. Furthermore, when individuals are working their metabolic pathways near maximal intensity, there may be more discrepancies to properly determine substrate selection based on its availability, ${ }^{14}$ although this speculation is not statistically proven and needs to be further researched. 
Previous research has mainly investigated endurance aerobic athletes, such as runners and cyclists, while there are limited studies on how fuel metabolism is effected in anaerobic athletes. There is a need for more extensive research to determine the how dietary intake effects physiological, metabolic, and performance measures in anaerobic athletes.

\section{Conclusion}

The results of this study demonstrate that moderate changes in dietary intake do not significantly affect fuel utilization during aerobic capacity exercise in resistance trained individuals. Furthermore, our findings suggest that moderate changes in $\mathrm{CHO}$ intake do not significantly benefit performance outcomes, We acknowledge that there are limitations to the study design that consequently limit the validity of conclusions that can be drawn. Considering the average exercise time in this study compared to others, there may not have been enough time for metabolic pathways to adjust to exercise intensity. This study also would have benefited from using blood plasma concentration as a measurement, to determine precise fuel utilization in exercising muscle. Implications from this study may suggest that in resistance trained individuals it may be more difficult to determine substrate oxidation during heavy exercise when metabolic pathways are working near maximum capacity, since there is less opportunity to select substrates based on availability. Also, resistance trained individuals may not be most accustomed to aerobic exercise which may modify reliable RER values. However, results from this study do indicate a need for further research on the effects of dietary intake in anaerobic athletes during maximal capacity exercise. Further investigations should include a more detailed diet protocol that provide more extreme differences between dietary conditions, as well as a need to incorporate innovative metabolic measures. 
Table 1. Descriptive statistics of subjects

\begin{tabular}{|c|c|c|c|}
\hline & $\operatorname{High} \mathrm{CHO}(\mathrm{n}=4)$ & Low $\mathrm{CHO}(\mathrm{n}=4)$ & Total $(\mathrm{n}=8)$ \\
\hline & Mean SD & Mean SD & Mean SD \\
\hline Age (years) & $25.75 \quad 5.61$ & $26.50 \quad 6.95$ & 26.125 .87 \\
\hline Height (inches) & $66.57 \quad 6.15$ & $70.75 \quad 2.18$ & $\begin{array}{ll}68.66 & 4.81\end{array}$ \\
\hline Weight (lbs.) & $161.2 \quad 44.9$ & $198.6 \quad 25.1$ & $\begin{array}{ll}180.0 & 39.2\end{array}$ \\
\hline $\mathrm{VO}_{2 \mathrm{MAX}}$ & $49.17 \quad 4.57$ & $48.95 \quad 6.56$ & $49.06 \quad 5.23$ \\
\hline
\end{tabular}

Table 2. Average macronutrient composition and total calories over five days based on subjects' long term dietary intake between high and low $\mathrm{CHO}$ diet conditions.

\begin{tabular}{|c|c|c|}
\hline & $\begin{array}{l}\text { High CHO } \\
\text { Mean SD }\end{array}$ & $\begin{array}{l}\text { Low CHO } \\
\text { Mean SD }\end{array}$ \\
\hline $\mathrm{CHO}(\%)$ & $51.29 \quad(5.1)$ & $42.40 \quad(6.6)$ \\
\hline Fat $(\%)$ & $26.57 \quad(7.6)$ & $30.10 \quad(6.0)$ \\
\hline Protein (\%) & $22.20 \quad(5.5)$ & $26.68 \quad(5.5)$ \\
\hline Total Calories & $2203.6(1091.9)$ & $2589.3(600.6)$ \\
\hline
\end{tabular}

Values presented as means (SD)

$\underline{\text { Table 3. Correlation between average carbohydrate intake and mean RQ values at each } \% \mathrm{VO}_{2} \max }$. RQ Values

\begin{tabular}{llllllllll} 
& RQ25 & RQ35 & RQ45 & RQ55 & RQ65 & RQ75 & RQ85 & RQ95 & RQ100 \\
\hline Avg. Carb Intake & -.391 & .308 & .285 & .010 & .658 & .386 & .621 & .627 & $.822^{*}$
\end{tabular}

$* p<0.05$ 
Figure 1. A comparison of mean $\mathrm{RQ}$ values at each $\% \mathrm{VO}_{2 \max }$ during the aerobic capacity test between conditions.

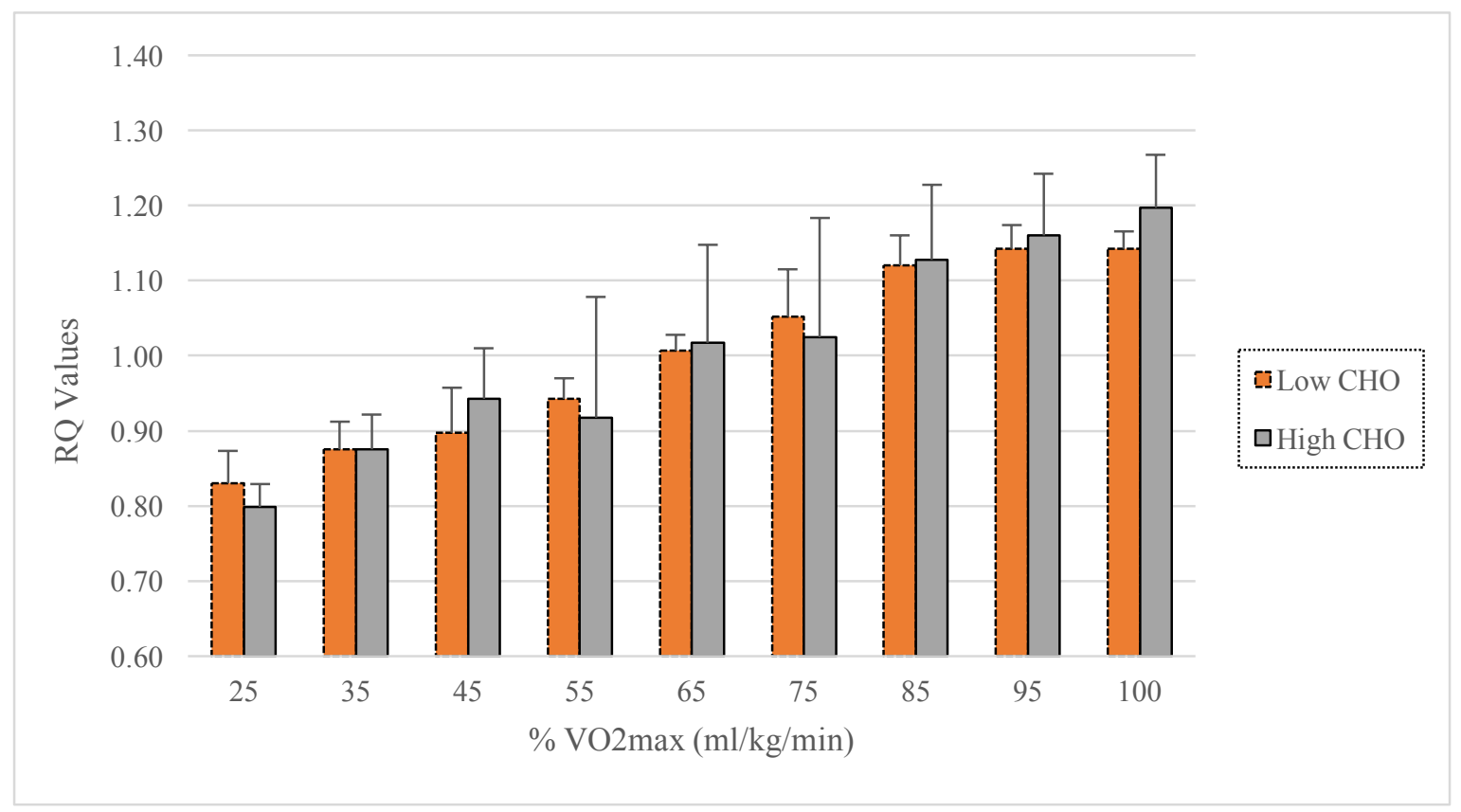

Figure 2. A comparison of mean $\% \mathrm{kcals}$ from $\mathrm{CHO}$ at each $\% \mathrm{VO}_{2 \max }$ during the aerobic capacity test between conditions.

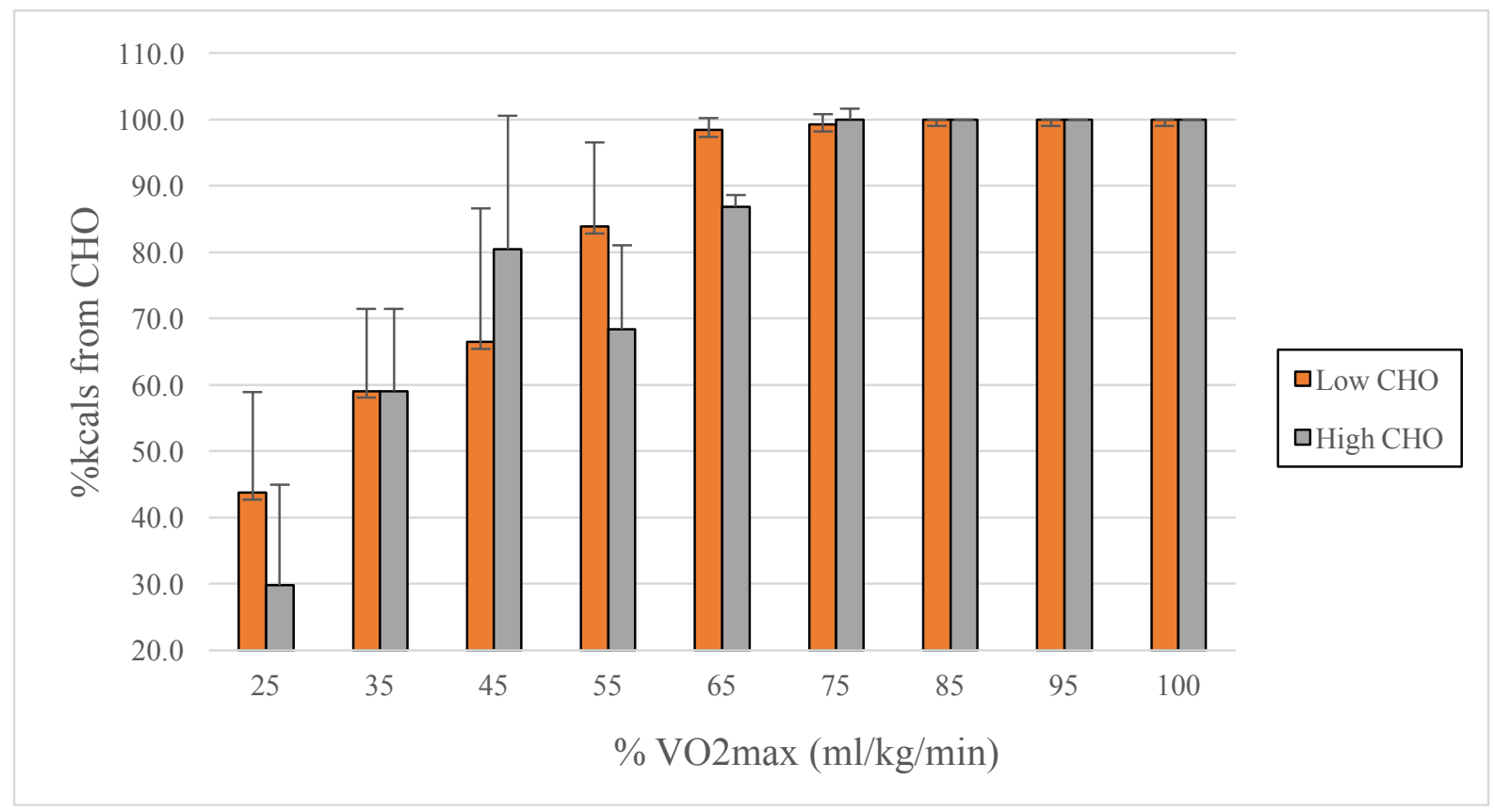


Figure 3. A comparison of mean $\%$ kcals from fat at each $\% \mathrm{VO}_{2 \max }$ during the aerobic capacity test between conditions.

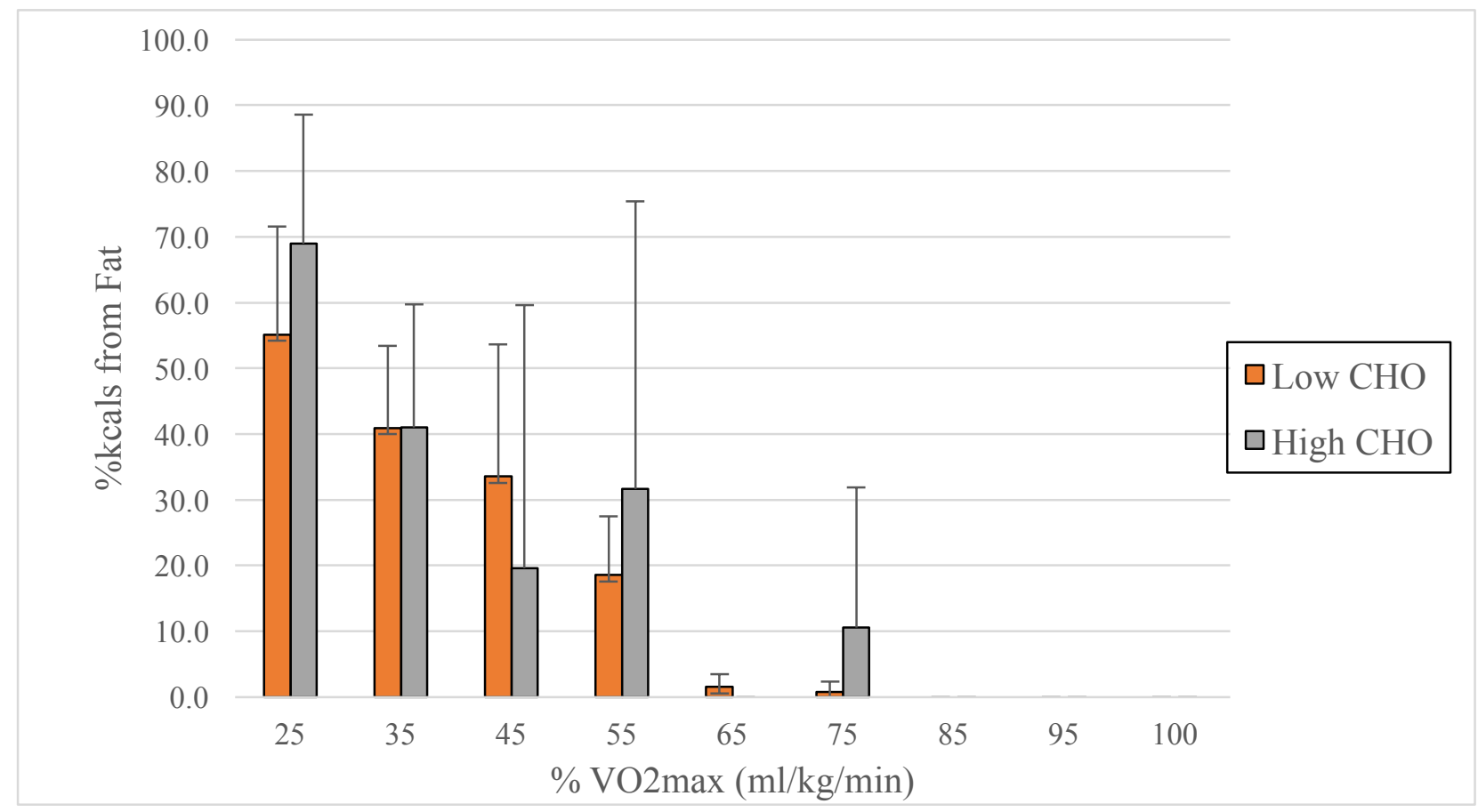




\section{References}

1. Romijn J.A., Coyle E.F., Sidossis L.S., Zhang X.J., Wolfe R.R. (1995). Relationship between fatty acid delivery and fatty acid oxidation during strenuous exercise. J Appl Physiol,79(6):1939-1945.

2. Jeukendrup A.E. (2003). High-carbohydrate versus high-fat diets in endurance sports. In. Vol 51: Schweizerische Zeitschrift fur;:17-23.

3. Romijn J.A., Coyle E.F., Sidossis L.S., et al. (1993). Regulation of endogenous fat and carbohydrate metabolism in relation to exercise intensity and duration. $A m J$ Physiol.;265(3 Pt 1):E380-391.

4. Katz A., Broberg S., Sahlin K., Wahren J. (1986). Leg glucose uptake during maximal dynamic exercise in humans. Am J Physiol.;251(1 Pt 1):E65-70.

5. Krogh A., Lindhard J. (1920). The Relative Value of Fat and Carbohydrate as Sources of Muscular Energy: With Appendices on the Correlation between Standard Metabolism and the Respiratory Quotient during Rest and Work. Biochem J.;14(3-4):290-363.

6. Hansen C. (1939b). Arbeitsfahigkeit und Ernahrung.

7. Pitsiladis, Y. P., Maughan, R. J. (1999). The Effects Of Alterations In Dietary Carbohydrate Intake On The Performance Of High-Intensity Exercise In Trained Individuals. European Journal of Applied Physiology 79.5

8. Pitsiladis Y.P., Duignan C., Maughan R.J. (1998). Effects of alterations in dietary carbohydrate intake on running performance during a $10 \mathrm{~km}$ treadmill time trial. $\mathrm{Br} J$ Sports Med.;30(3):226-231.

9. Williams C., Brewer J, Walker M. (1996). The effect of a high carbohydrate diet on running performance during a 30-km treadmill time trial. Eur J Appl Physiol Occup Physiol. 1992;65(1):18-24.

10. Zajac A., Poprzecki S., Maszczyk A., Czuba M., Michalczyk M., Zydek G. (2014). The effects of a ketogenic diet on exercise metabolism and physical performance in off-road cyclists. Nutrients.;6(7):2493-2508.

11. Helge J.W., Wulff B., Kiens B. (1998). Impact of a fat-rich diet on endurance in man: role of the dietary period. Med Sci Sports Exerc.;30(3):456-461.

12. Langfort J., Pilis W., Zarzeczny R., Nazar K., Kaciuba-Uściłko H. (1996). Effect of lowcarbohydrate-ketogenic diet on metabolic and hormonal responses to graded exercise in men. J Physiol Pharmacol.;47(2):361-371. 
13. Burke L.M., Hawley J.A., Angus D.J., et al. (2002). Adaptations to short-term high-fat diet persist during exercise despite high carbohydrate availability. Med Sci Sports Exerc.;34(1):83-91.

14. Muoio D.M., Leddy J.J., Horvath P.J., Awad A.B., Pendergast D.R. (1994). Effect of dietary fat on metabolic adjustments to maximal VO2 and endurance in runners. Med Sci Sports Exerc.;26(1):81-88.

15. Phinney S.D., Bistrian B.R., Evans W.J., Gervino E., Blackburn G.L. (1983). The human metabolic response to chronic ketosis without caloric restriction: preservation of submaximal exercise capability with reduced carbohydrate oxidation.

Metabolism.;32(8):769-776.

16. Helge J.W., Richter E.A., Kiens B. (1996). Interaction of training and diet on metabolism and endurance during exercise in man. $J$ Physiol.;492 ( Pt 1):293-306.

17. Carey A.L., Staudacher H.M., Cummings N.K., et al. (2001). Effects of fat adaptation and carbohydrate restoration on prolonged endurance exercise. $J$ Appl Physiol (1985).;91(1):115-122.

18. McArdle W.D., Katch F.I., Katch V.L. Exercise Physiology: Nutrition, Energy, and Human Performance. Eighth ed: Philadelphia : Wolters Kluwer Health/Lippincott Williams \& Wilkins,; 2015.

19. Simonsen J.C., Sherman W.M., Lamb D.R., Dernbach A.R., Doyle J.A., Strauss R. (1991). Dietary carbohydrate, muscle glycogen, and power output during rowing training. J Appl Physiol (1985).70(4):1500-1505.

20. Sherman W.M., Costill D.L., Fink W.J., Miller J.M. (1981). Effect of exercise-diet manipulation on muscle glycogen and its subsequent utilization during performance. Int $J$ Sports Med.2(2):114-118.

21. Patterson R., Potteiger J.A. (2011). A comparison of normal versus low dietary carbohydrate intake on substrate oxidation during and after moderate intensity exercise in women. Eur J Appl Physiol.111(12):3143-3150.

22. Putman C.T., Spriet L.L., Hultman E., et al. (1993). Pyruvate dehydrogenase activity and acetyl group accumulation during exercise after different diets. Am J Physiol.265(5 Pt 1):E752-760.

23. Gaskill S.R., Walker A.J., Sanchez A.O., Serfass R.A., Leon A.S. (2001). Validity and reliability of combining three methods to determine ventilatory threshold. Medicine \& Science in Sport \& Exercise.33:1841-1848. 


\title{
CHAPTER II
}

\section{EXTENDED REVIEW OF THE LITERATURE}

\author{
Specific Research
}

It is known that in order to produce mechanical energy through muscular activity, the body must oxidize carbohydrate, fat, or protein through metabolic processes. This results in the production of ATP as mechanical energy. Total body metabolism, specifically skeletal muscle depends on factors such as training status, intensity and duration of exercise, and substrate availability. During exercise at low intensities (25\% of VO2 max) fat is the primary macronutrient that is oxidized for energy ${ }^{1,24}$. As the exercise intensity progresses, $\left(65 \%\right.$ of $\left.\mathrm{VO}_{2 \max }\right)$ there is an alteration in skeletal muscle substrate utilization, which results in mainly the use of carbohydrate energy ${ }^{1}$. Research suggest that skeletal muscle prefers the use of peripheral sources at lower intensities, rather than intramuscular stores ${ }^{1,25}$. Intramuscular stores of carbohydrate and fat via muscle glycogen and muscle triglyceride are favorable at high intensity exercise, muscle glycogen more so than intramuscular triglyceride $(85 \% \text { of } \mathrm{VO} 2 \mathrm{max})^{1,25}$.

Duration of exercise also effects which macronutrient is utilized during certain time periods and the intensity of exercise at that specific point. It is clear that at moderate intensities (60-80\% $\left.\mathrm{VO}_{2 \max }\right)$ individuals performing 1-3 hours of continuous exercise result in fatigue and carbohydrate depletion ${ }^{1}$. During the early portions of exercise the majority of carbohydrate energy comes from muscle glycogen. However, during prolonged exercise, muscle glycogen/ concentration decreases as exercise progresses. There then becomes an increased dependence on plasma blood glucose, as fuel utilization in skeletal muscle. 
An individual's dietary composition (percentage of carbohydrate, fat, protein) can affect which macronutrient is utilized during exercise based on its stores and availability. Substrates that fuel exercising muscle are available through endogenous (liver and muscle glycogen) and exogenous (plasma glucose and free fatty acids) stores. Current literature shows that the amount of muscle glycogen and blood glucose correlate with duration performance until fatigue ${ }^{26}$.

During exercise fatigue develops once muscle glycogen and plasma glucose are depleted of their stores. The more glycogen that is available in its stores the longer an individual will be able to perform until fatigue. It has also been found that glycogen availability affects the utilization of other substrates during exercise, especially at higher intensities. This is mainly due to the fact that muscle mainly prefers to utilize glycogen as a fuel source during exercise Furthermore, a magnitude of studies suggest that fat oxidation is increased in individuals that participate in a low regimen carbohydrate diet (low $\mathrm{CHO}$ ). These studies include low $\mathrm{CHO}$ intake ranging from $5-40 \%$, compared to those on a high carbohydrate diet (high CHO), ${ }^{8,21,27-29}$ The differences in fuel utilization is most likely due to lower availability of muscle glycogen and blood glucose, and increased cellular and enzymatic adaptions to increase fat oxidation capacity. Thus, the rate of plasma FFA uptake increases, inhibiting carbohydrate oxidation. This is also true when trained individuals are participate in a high fat diets. Previous investigations have suggested that endurance athletes that partake in high fat and low CHO diets, working at a moderate intensity, tend to perform better than individuals on high $\mathrm{CHO}$ diet in conjunction with low fat diets ${ }^{3,10}$. Conversely research has also suggested that high $\mathrm{CHO}$ and moderate fat diets improve performance for trained individuals working at high intensities while participating in longer endurance events. $^{9}$ 
Current level of fitness depends on how an individual uses and oxidizes substrates due to adaptions in gene expression and increased enzyme expression resulting in greater total number of enzymes and mitochondria. Trained individuals can oxidize fat at higher rates during absolute and relative exercise intensity ${ }^{3}$. Research suggests that trained individual's maximal rate of fat oxidation are between intensities of $59 \%$ and $64 \%$ of $\mathrm{VO}_{2}$ max, compared to the general population at 47 and $52 \%$ of $\mathrm{VO}_{2}$ max. Thus, trained individuals tend to utilize more intramuscular triacylglycerol compared to untrained individuals ${ }^{3}$.

There is limited research on the effects of diet on performance in anaerobic athletes, as well as comparing a variety of diets and how this may affect fuel metabolism during incremental graded exercise test. While there are a multitude of studies that investigate short term dietary interventions, there is limited information on long term diets. Additionally, there are inconclusive findings on the time duration as to when physiological adaptions occur at the muscular level as a result of changes in dietary composition. Some studies suggest that adaption may occur at only two days while other suggest that it takes four to six weeks for an individual to adapt to changes in dietary composition.

This review will investigate a variety of short term and long term dietary interventions, and how they affect fuel utilization in exercising skeletal muscle, as well as performance in trained individuals. The majority of this investigation will include articles that require trained individuals to work at intensities involving light, moderate, and high intensity exercise, comprising a variety of exercise durations ranging from 10 to 200 minutes of exercise time. 
Fuel Metabolism during Various Intensity Exercise

Fuel metabolism is derived from different sources depending on intensity as well as exogenous and endogenous substrate availability ${ }^{25}$. Exogenous substrates used during exercise include blood glucose and plasma fatty acids, while endogenous substrates include muscle glycogen and intramuscular triglycerides. Additionally, an alternate source of glucose can be stored in the muscle and in the liver as glycogen ${ }^{30}$. Dependent on diet and physical activity level, most glycogen is stored in muscle and about $80 \mathrm{~g}$ are stored in the liver ${ }^{25}$. During light exercise $\left(25 \%\right.$ of $\left.\mathrm{VO}_{2 \max }\right)$ most of the energy required comes from plasma fatty acids transported from adipose tissue into circulation ${ }^{31}$. As exercise intensity increases initially muscle glycogen and blood glucose will equally predominate, until glycogen stores are completely depleted ${ }^{25}$. Once glycogen stores become depleted, muscle is unable to oxidize fat at high intensities, due to decreased albumin availability for transportation of plasma FFA to the muscle cell. In order to adapt to a fat oxidation state an individual would have to decrease their power output to about $\left(30-50 \% \mathrm{VO}_{2 \max }\right)$ that is equivalent to the body's ability to predominately oxidize fat as a fuel source $^{25}$. Although this is contingent upon the amount of intramuscular triglycerides stores, since they can be maximally oxidized at $65 \%$ of $\mathrm{VO}_{2}$ max as a fuel source during high intensity exercise. Carbohydrate intake in relation to muscle glycogen levels on endurance capacity has been studied for many years and it appears from numerous investigations that the amount of initial glycogen stored is contingent to the time of exercise until exhaustion, this is specifically true for endurance athletes ${ }^{25,11,16,31}$.

A study by Romijn et al. ${ }^{1}$ randomly assigned five endurance trained cyclist to participate in three consecutive days of different intensity exercise $\left(25,65,85 \% \mathrm{VO}_{2 \mathrm{Max}}\right)$. The purpose of this study was to determine the effects of exercise intensity and duration on endogenous FFA 
utilization. Romjin hypothesized that lipolysis in adipocytes would be greatest during low intensity exercise and lipolysis of muscle triglyceride oxidation would be stimulated at higher exercise intensities.

In this investigation, they measured plasma concentrations and substrate oxidation rates after 30,60, and 90 minutes of exercise at each intensity. They found that at 30 minutes of exercise FFA concentrations were highest during $25 \%$ of $\mathrm{VO}_{2 \max }$ at, $.97 \mathrm{mmol} / \mathrm{l}$. While there was an initial decrease in FFA concentration at $65 \%$, they progressively increased to $.90 \mathrm{mmol} / \mathrm{l}$; and concentrations were lowest at $85 \%$, at $.52 \mathrm{mmol} / \mathrm{l}$, and continuously decreased with duration. Plasma glucose concentrations directly increased with exercise intensity at 30 minutes of exercise, and following 90 min of exercise, glucose concentrations remained stagnant at $25 \%$ and $65 \%$ of $\mathrm{VO}_{2 \max }$, and/or decreased at $25 \%$ of $\mathrm{VO}_{2 \max }$.

Substrate oxidation rates during exercise exhibited a significant difference in respiratory exchange ratio (RER) during each increment of $\mathrm{VO}_{2}$ max, RER at each intensity were as follows, $0.73,0.83,0.91(25 \%, 65 \%$, and $85 \%)$. Presenting that fat oxidation mainly occurred during $25 \%$ of $\mathrm{VO}_{2 \max }$, whereas carbohydrate oxidation significantly increased during 20-30 minutes with increasing intensity exercise. They also found that whole body carbohydrate oxidation at $65 \%$ and $85 \%$ of $\mathrm{VO}_{2 \max }$ were significantly higher than the amount of glucose uptake into the muscle. Both values increased as intensity increased, but glucose tissue uptake was significantly decreased compared to total body oxidation. This shows that there was minimal association of muscle glycogen to whole body carbohydrate oxidation at 20-30 minutes of exercise. However, muscle glycogen utilization significantly increased with exercise intensity and was the dominant substrate utilized at $85 \%$ of $\mathrm{VO}_{2 \max }$, after $30 \mathrm{~min}$ of exercise. This coincides with a study done by Katz et al. ${ }^{4}$, which insinuates that fuel substrate in the form of carbohydrate availability is 
most pertinent during progressive exercise, specifically muscle glycogen being the biggest contributor of energy during high intensity exercise. Katz et $\mathrm{al}^{4}$ measured leg glucose uptake (LGU) during submaximal $\left(50 \% \mathrm{VO}_{2 \max }\right)$ and maximal dynamic exercise $\left(97 \% \mathrm{VO}_{2 \max }\right)$. Glucose, lactate, and G-6-P increased significantly during maximal exercise but not during submaximal exercise. Although, blood glucose increased it was a minor contributor overall, and it appears that the rate of glucose utilization is lower than the rate of glucose uptake into the muscle. This shows that the amount of glycogen and blood glucose doesn't seem to limit performance outcomes during maximal aerobic power, since minor fraction of blood glucose was utilized, and $50-60 \%$ of glycogen remained in the vastus lateralis even after fatigue ${ }^{32}$. Unlike carbohydrate oxidation, there was no evidence of a direct relationship between fat oxidation rates and exercise intensity. After 30 minutes of exercise there were significantly higher fat oxidation rates at $65 \%$ compared to $25 \%$, and $85 \%$ of $\mathrm{VO}_{2 \max }$. Interestingly, there was no difference in oxidation rates between intensities of $25 \%$ and $85 \%$ of $\mathrm{VO}_{2 \max }$, other than the threefold increase in energy expenditure. Although, plasma FFA contributed to the majority of fat oxidation during $25 \%$ of $\mathrm{VO}_{2 \max }$, both $\mathrm{FFA}$ and muscle triglyceride stores contributed equally to fat oxidation at $65 \%$.

From these studies, we can assume that in endurance trained males, fat fuel substrates provide a larger amount of energy, although the rate at which they can be oxidized is limited to albumin availability, and enzyme saturation. Therefore carbohydrate oxidation is required in order to fuel exercising muscle tissue during increasing intensity exercise ${ }^{25}$. FFA are predominately utilized at intensities of $25 \%$ of $\mathrm{VO}_{2 \max }$, and intramuscular triglycerides are maximally used at $65 \%$, but levels do not increase as intensity increases to $85 \%$ of $\mathrm{VO}_{2 \max }{ }^{1}$. As exercise intensity increases FFA utilization decreases due to insufficient albumin transport from 
adipose to muscle tissue ${ }^{25}$, it is counterbalanced by an increase in muscle glycogenolysis in accordance with plasma glucose uptake into the muscle cell.

The Effects of Dietary Carbohydrate Alterations on Exercise Metabolism

The physiological aspect of carbohydrate oxidation during exercise depends on a couple of factors. Current literature supports that substrate oxidation is influenced by substrate availability, intensity of exercise ,training, and duration ${ }^{21,26}$. Carbohydrate oxidation may occur in two different ways. One is the transport of glucose to the glycolytic pathway through the breakdown of glycogen into glucose (glycogenolysis) from muscle glycogen, or the uptake of plasma glucose mediated by insulin sensitive GLUT-4 transporters ${ }^{1,31,33}$. The amount of dietary carbohydrate impacts hormone levels, specifically insulin, and blood glucose responses in the body $^{31}$. Blood glucose levels have a direct relationship with insulin levels and glucose uptake into the muscle cell. For example, a low $\mathrm{CHO}$ diet will result in reduced blood glucose levels due to the lack of carbohydrate. This results in decreased levels of insulin, released from the pancreatic beta cells. Low concentrations of insulin are associated with decreased glucose uptake into muscle cell, reflected by the small amount of GLUT-4 transporters at the cell's surface. Whereas an increase in insulin concentration, as a result of a high-CHO diet, upregulates translocation of GLUT-4 to the cell membrane and thus increases glucose uptake into the muscle cell. Glucose can then be broken down and used to produce ATP through the glycolytic pathway.

This physiology agrees with various investigations which reported that those participating in a low $\mathrm{CHO}$ diet compared to either a high $\mathrm{CHO}$, or moderate $\mathrm{CHO}$ (mod-CHO) diet, resulted in decreased $\mathrm{CHO}$ oxidation and increased fat oxidation in trained individuals running at a 
moderate intensity ${ }^{5-7,21,22}$. Some of the first recognized studies by Krogh and Lindhard ${ }^{5}$; Christensen \& $\operatorname{Hansen}^{6}$ (1939b), found that individuals on a low carbohydrate (low-CHO) and high fat diet resulted in a lower respiratory exchange ratio (RER) and decreased endurance capacity, while those on a high carbohydrate (high-CHO) resulted in an elevated RER and endurance capacity compared to those in the low CHO group. Similarly, Christensen \& Hansen designed a similar study and found that low $\mathrm{CHO}$ diets enhanced a state of ketosis and negated aerobic performance until fatigue, which followed with low blood glucose levels throughout exercise. The high CHO group sustained blood glucose levels and increased endurance capacity. These studies insinuate that a reduction in carbohydrate intake resulted in a decreased reliance on carbohydrate energy and increased fat oxidation as fuel, while causing adverse effects to endurance capacity. Conversely, an increase in carbohydrate intake resulted in elevated carbohydrate oxidation and increased endurance capacity. These findings are generalizable to a majority of studies that have examined the effects of dietary intake on fuel metabolism during endurance capacity exercise. For example, Patterson et al. ${ }^{21}$ reported that during exercise (55\% $\left.\mathrm{VO}_{2 \max }\right)$ trained women, participating in a low $\mathrm{CHO}(20 \%)$, on average, had a $13.5 \%$ increase in percentage of total energy expenditure (TEE) from fat, compared to those on a mod-CHO (55\%) diet. The authors suggested that low $\mathrm{CHO}$ diets may be an effective way for individuals to promote fat oxidation during moderate intensity exercise. This is also in agreement with a study by Putman et. al ${ }^{22}$, that suggest subjects following a 6-day low $\mathrm{CHO} \operatorname{diet}(<3 \%$ of energy) compared to those following a high $\mathrm{CHO}(86 \%)$, had maximally activated PDHa activity in the first 15 minutes of exercise, but didn't reach the same levels that the high CHO diet. PDHa is an enzyme that plays a crucial role and is associated with carbohydrate oxidation. Presenting that there was an impaired capacity of carbohydrate oxidation in the low CHO group and perhaps 
promoted fat oxidation for the remaining length of exercise. Pitsiladis's, study also suggests that runners following a 7 day high $\mathrm{CHO} \operatorname{diet}$ (55\% 4 days, increased $70 \%$, for remaining 3 days) had significantly higher rate of carbohydrate oxidation compared to those following a 7 day low CHO (40\%) during a $10 \mathrm{~km}$ treadmill test.

Additionally, subjects in the high $\mathrm{CHO}$ also had higher blood glucose levels during exercise but weren't significantly different to those in the low CHO group, since the diet alterations across each group remained moderately changed. But, there was a significant increase in blood glucose levels from pre-to post exercise in both the low $\mathrm{CHO}$ and high $\mathrm{CHO}$ groups. The high $\mathrm{CHO}$ group showed an increased utilization of $\mathrm{CHO}$, due to increased levels of blood glucose, upregulating carbohydrate oxidation in exercising muscle. These studies may propose that dietary carbohydrate intake effects blood glucose concentrations and adaptations to carbohydrate enzymatic activity level, both of which are major determinants on the rate of glucose uptake and oxidation by muscle.

Once research diverged to different athletic events findings started to become inconsistent with the generalizations of early research. Research indicated that different intensities and durations of exercise also influence fuel metabolism. Pitsiladis et al. ${ }^{8}$ reported that moderate changes in dietary carbohydrate had no effect on performance in trained runners during a 10km run. This crossover study had subjects follow a normal CHO diet (55\%) for 7 days, and then groups were randomly assigned to high $\mathrm{CHO}$ (55\% 4 days, and then $70 \%$ for 3 days), or low CHO (40\%) for 7 days. Subjects then performed a $10 \mathrm{~km}$ trail run at $4 \%$ grade at $80 \%$ of their $\mathrm{VO}_{2 \max }$. Average time until the $10 \mathrm{~km}$ was reached was no different between conditions. Although, the definition of a "low carb diet" can be misconstrued in the study, subjects in the low $\mathrm{CHO}$ on average consumed $350 \mathrm{~g}$ per day, which is much greater than other studies that use a 
low $\mathrm{CHO}$ condition. These results are consistent with Sherman et al. ${ }^{20}$ who also reported that carbohydrate loading did not benefit performance since there were no differences in performance run times, or post-exercise glycogen levels in trained runners during $20.9 \mathrm{~km}$ run. Despite this, the Pitsiladis et al. ${ }^{8}$ methodology didn't include muscle glycogen levels, these studies may suggest that an increased or decreased availability of muscle glycogen have no difference in performance or exercise capacity when consuming a low $\mathrm{CHO}$ or high $\mathrm{CHO}$ diet in running events with a duration of $<90$ minutes in trained individuals ${ }^{8}$. Although, low $\mathrm{CHO}$ diets have been found to have detrimental effects to performance during high intensity exercise since it was found to have adverse effects on fluid and electrolyte balance, which offsets cardiovascular function $^{34}$. Overall, improved performance on low $\mathrm{CHO}$ diets is likely because trained individuals are able to oxidize fat at higher rates, and the low $\mathrm{CHO}$ group, being endurance runners were able to use a large portion of their energy through fat oxidation, and sustain their performance ${ }^{3}$. Whereas, the high $\mathrm{CHO}$ group had a higher availably of muscle glycogen and thus a large portion of their energy relied on $\mathrm{CHO}$ oxidation.

Williams et al. ${ }^{9}$, reported inconsistent findings to those of Pitsiladis et al. ${ }^{8}$ and Sherman et al. ${ }^{24}$. Eighteen runners on a high $\mathrm{CHO}$ supplementation resulted in an increased performance compared to those on a normal mixed diet regimen, during a $30 \mathrm{~km}$ treadmill time trial. All subjects ran 2 time trials, during the first-time trial all subjects performed on their normal diet. After subjects were randomly assigned to 7 days of a control (normal diet) or high $\mathrm{CHO}$ diet. During the second-time trial, 6 men ran faster during the last $5 \mathrm{~km}$ of their time trial compared to trial 1 on their normal diet. Although there were no overall significant differences in performances times between groups. These overall findings on the effects of carbohydrate intake on performance may advocate that trained individuals, working at a moderate intensity, partaking 
in longer endurance events may improve their performance following a high $\mathrm{CHO}$ diet, and that dietary carbohydrate has no effect on performance when partaking in during short duration exercise $(<90 \mathrm{~min})$.

There seems to be a clear understanding of the effects of dietary carbohydrate at moderate intensity exercise and duration. Although there are inconsistent findings, there is a clear relationship between carbohydrate intake and moderate intensity exercise as it relates to duration. There is a less prominent relationship that follows when dietary carbohydrate composition is altered when performing at high intensity exercise.

Sherman et al.1993 reported that training on moderate $\mathrm{CHO}$ intake $(55 \%)$ resulted in a significantly decreased muscle glycogen levels compared to the high $\mathrm{CHO}$ group, but had no effect on total time until exhaustion during treadmill test lasting 60 minutes at $75 \%$ of $\mathrm{VO}_{2 \max }$. Although, research studies show that the implications of a low $\mathrm{CHO}$ diet, may stimulate protein utilization as fuel, especially after glycogen depleting exercise ${ }^{34}$. A study by Lemon and Mullin ${ }^{35}$ demonstrated that when exercise induced a glycogen depleting state followed by 1 day of a low CHO diet, protein breakdown contributed to about $10 \%$ of TEE. These findings demonstrate the adverse effects that this may have on trained individuals and their performance.

An earlier study by Pitsiladis et al. ${ }^{7}$, examined the effects of dietary carbohydrate intake on performance during high intensity exercise. The purpose was to determine whether moderate carbohydrate modifications would affect the performance of high intensity exercise at $90 \%$ of $\mathrm{VO}_{2 \max }$ lasting $10 \mathrm{~min}$ and $80 \%$ of $\mathrm{VO}_{2 \max }$ lasting $30 \mathrm{~min}$, in well trained cyclist and triathletes. Subjects completed 4 cycle ergometer tests until exhaustion along with 3 different diet conditions, including their normal diet, which averaged about 55\% of CHO intake, and two diet conditions including a high $\mathrm{CHO}(71 \%)$ and low $\mathrm{CHO}(40 \%)$. All subjects were started off with 
a familiarization cycle capacity trial followed by 7 days of their normal dietary intake, and then participated in another familiarization trail, followed by 6 days of a normal diet and then randomly assigning subjects to 7 days of either low/high $\mathrm{CHO}$ group. Subjects then completed an experimental cycle capacity test on their diet condition. After the first experimental trail subjects again followed a 6-day normal diet intake, and then 7 days of the diet condition they hadn't previously done (high/low $\mathrm{CHO}$ ), followed by an experimental cycle capacity test. The authors found that during familiarization trials at 90\% of max (EXP1) and $80 \%$ max (EXP2) the high $\mathrm{CHO}$ group had the longest time to exhaustion although there were no significant difference in time to exhaustion between diets. There was also no difference in cardiorespiratory and ventilatory measures $\left(\mathrm{VO}_{2}, \mathrm{HR}\right)$. At $80 \%$ of $\mathrm{VO}_{2 \max }$ there was a significant difference in RER between diets, at the minute 15 the high $\mathrm{CHO}$ group averaged .91 and the low $\mathrm{CHO}$ averaged .87 .

Blood metabolites were also measured and they found that in EXP 2 at $80 \%$ of max there was a significant increase between diet conditions on lactate concentrations at 5 and 10 minutes, and significant decrease in plasma glycerol concentrations at 10- 20 minutes of exercise following a high $\mathrm{CHO}$ diet. Overall the results of this study determine that moderate alterations in $\mathrm{CHO}$ intake during high intensity exercise have no significant effect on performance.

\section{The Effects of Dietary Fat Alterations on Exercise Metabolism}

In accordance with carbohydrate oxidation, fat oxidation is also influenced by substrate availability, intensity of exercise, and duration. There are various forms of fuel sources that can be utilized during fat oxidation, also known as lipolysis. Lipolysis is responsible for the catabolic reaction (hydrolysis) of triacylglycerols in cellular lipid tissues. During lipolysis exercising 
muscle utilizes fat energy at various intensities through endogenous and exogenous substrates. The exogenous substrates include: non- esterified fatty acids (NEFA) or plasma free fatty acids (FFA) and triacylglycerol's (TAG). These substrates are always present in the blood plasma, and have a relatively quick turnover rate, since they are always being utilized and replaced ${ }^{31}$. Plasma NEFA's enter the blood stream through adipose tissue via the activation of enzyme hormone sensitive lipase (HSL). HSL activates a catabolic reaction in adipose tissue that converts stored triglycerides into smaller molecules known as NEFA's. From there the NEFA's enter circulation, but must be bound and carried by a plasma protein, albumin, due to its water insoluble properties $^{31}$. Additionally, this means that the current concentration of NEFAs in the plasma determines their rate of release by the enzyme HSL, from adipose tissue. Plasma NEFA levels are directly related to their rate of utilization. Thus, the higher concentration of NEFAs, the higher their rate of utilization is in muscle tissues ${ }^{31}$. Plasma TAG are another fuel substrate used by muscle tissue to produce ATP energy. NEFAs can enter the muscle cell once they are hydrolyzed from TAG by the enzyme lipoprotein lipase. Which will result in three free fatty acids and a glycerol backbone. Lastly, the endogenous substrate includes intramuscular triglycerides, which are lipid droplets stored within muscle fibers and are utilized during intramuscular lipolysis ${ }^{25}$.

As stated previously in a study by Romijn et al. ${ }^{1}$, plasma FFA are predominately utilized at $25 \%$, while intramuscular triglycerides are maximally used at $65 \%$ of $\mathrm{VO}_{2 \max }$. While they did not provide subject's dietary intake, all subjects were in a 10-12 hour fasted state. Current literature has inconsistent findings on the manipulation of dietary fat intake on fuel metabolism and performance. Numerous studies have found that high fat, low $\mathrm{CHO}$ (ketogenic) diets result in increased fat oxidation as well as an improvement or no difference in performance ${ }^{10-14}$. While 
other investigations reported that high carbohydrate diets either improved or didn't change endurance performance, compared to high fat diets ${ }^{16,17}$. In humans, it is unclear when exactly adaption to high fat diet at the muscular level occurs. Some studies have seen changes as quick as 7 days, with improved performance, while other studies have reported adaptations to occur after 4-7 weeks, with no change, increased or decreased performance of diet modifications ${ }^{11}$

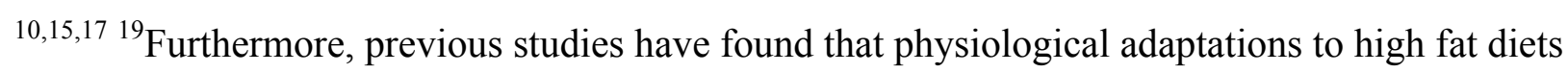
result in an increase capacity to transport, oxidize and store fat in muscle due to increased carnitine palmitoyl transferase 1 (CPT-1) gene expression ${ }^{3}$.

Zajac et al. ${ }^{10}$, examined the effects of a 4-week ketogenic and mixed diet on exercise metabolism and performance in 8 male, endurance cyclists. This crossover study design included a mixed diet of $50 \%$ carbohydrate, $30 \%$ fat, and $20 \%$ protein, the ketogenic diet included $15 \%$ carbohydrate, $70 \%$ fat, and $15 \%$ protein. Subjects were required to work for 105 minutes on a cycle ergometer with various intensities. The first $90 \mathrm{~min}$, included working at $85 \%$ of their lactate threshold (LT) and the last 15 minutes at 115\% of LT. RER was obtained throughout the duration of the test and venous blood samples were taken at 45 and 90 min, and after maximal effort was achieved. RER was significantly lower in the ketogenic diet at rest and 45 minutes of exercise. There was no significant difference at maximal exercise. FFA concentrations were increased significantly at each measurement from rest to maximal exercise in the ketogenic diet compared to a mixed. Performance of $\mathrm{VO}_{2 \max }$, and $\mathrm{VO}_{2} \mathrm{LT}$ in the ketogenic diet improved significantly compared to the mixed diet, but decreased performance in LT workload and max workload. The authors suggest that long term high fat diets may be beneficial for long duration events in aerobic athletes working at high volume and low to moderate intensity training. Likewise, ketogenic diets tend to be detrimental to performance at high intensities due to lack of 
muscle glycogen content and glycolytic gene expression activity ${ }^{10}$. Although, results are questionable due to lack of subjects in this study.

In contrast Helge et al. ${ }^{16}$, studied subjects after 7 weeks on a high fat diet and found dissimilar results. Subjects either followed a high fat $\operatorname{diet}(21 \% \mathrm{CHO}, 60 \%$ fat, $17 \%$ protein) for 7 weeks and then switched to a high carbohydrate $(65 \% \mathrm{CHO}, 20 \%$ fat, $17 \%$ protein) for one week, while the control group followed the high $\mathrm{CHO}$ diet for 8 weeks. There was an $11 \%$ increase in $\mathrm{VO}_{2 \max }$ in both diet groups, as well as time until exhaustion at $82 \%$ of $\mathrm{VO}_{2 \max }$. But, the results were more prominent in the 8 -week high carb diet, as time to exhaustion increased 35 minutes in the high fat diet and 102 minutes in the high CHO diet. Helge et al. ${ }^{11}$ continued this study using the same dietary intake and training regimen, but using a short term diet and found similar results to Zajac et al. ${ }^{10}$. Helge reported improvements in performance after 2 and 4 weeks on a high fat diet. After 4 weeks' improvements were seen in endurance capacity in both groups with a significant increase, but more so in the high fat group. RER was also significantly lower in the high fat group during exercise. The authors concluded that endurance performance was improved after 2 and 4 weeks on a high fat and high carbohydrate diet, but a high fat diet may be unfavorable to endurance performance when sustained for longer than 4 weeks.

An earlier study by Phinney et al. ${ }^{15}$ found that well trained cyclist following a high fat diet for 4-6 weeks resulted in an increased fat oxidation and overall maintenance in endurance capacity performance. Subjects tracked 1 week of a eucaloric balanced diet (EBD) consisting of $1.75 \mathrm{~g} / \mathrm{kg}$ protein, $2 / 3$ carbohydrate, $1 / 3$ fat, from total calories which represented the control diet. Subject then followed the 1 week control diet with 4 weeks of a eucaloric ketogenic diet (EKD), $<20 \mathrm{~g}$ of carbohydrate daily). At the end of the control diet EBD-1 and after 4 weeks of the EKD diet subjects performed an endurance capacity test at $60-65 \%$ of their determined $\mathrm{VO}_{2 \max }$. 
Results of the endurance capacity test at $60-65 \%$ of $\mathrm{VO}_{2 \max }$ were as follows, three subjects rode longer after the EKD-4, while two subjects rode longer after EBD-1. The mean time during the test for EKD-4 was $151 \mathrm{~min}$ and $147 \mathrm{~min}$ for EBD-1, with an insignificant difference. There was a significant decrease in RER in the EKD-4 group. The mean RER decreased from .83 in 1-EBD, to .72 in the 4- EKD. Suggesting that fat oxidation was promoted in the ketogenic group.

Although, the findings seem to accompany limitations due to the inconsistent results between subjects and a small subject group of 5 trained cyclists. Overall, there was no change in performance but individual results ranged from a 36\% decrease and $57 \%$ increase in performance between subjects. The authors concluded that well- trained individuals following a ketogenic diet wouldn't compromise performance since the physiological adaptation successfully utilized fat as the predominant muscle substrate at submaximal intensity while still maintaining performance.

\section{Summary}

In conclusion to this review, it is evident that the effects of dietary alterations in carbohydrate and fat effect how chemical energy is metabolized in muscle to produce ATP and use as mechanical energy during exercise. These alternations effect fuel metabolism which are influenced by substrate availability, gene expression/ adaptation, intensity and duration of exercise, and hormonal response to exercise. When a mixed diet is consumed, plasma free fatty acids are the main substrate utilized during low intensity exercise. As exercise intensity increases $\left(65-85 \%\right.$ of $\left.\mathrm{VO}_{2 \max }\right)$ there is a progressive decline in FFA concentrations which is offset by an increased reliance on carbohydrate energy. Specifically, plasma glucose uptake and particularly muscle glycogen utilization during high intensity exercise. Carbohydrate intake tends to make 
the most prominent effect on which substrates are oxidized based on its availability through endogenous and exogenous sources. In general, an increase in dietary carbohydrate intake results in higher carbohydrate oxidation rates due to an increase in plasma glucose and muscle glycogen. This is especially true when trained individuals are participating in prolonged, moderate intensity exercise. On the contrary, a decrease in carbohydrate intake increases fat oxidation rates due to a higher availability of plasma fatty acids and intramuscular triglycerides. This can also result in greater protein oxidation rates, and possibly decrease the rate of protein synthesis. Although, protein metabolism is not seen as a major fuel source, even when carbohydrate intake is low, the possible adverse effects should not be overlooked when the goal is to preserve lean body mass, improve training, and performance.

Typically, carbohydrate intake has no effect on performance when trained individuals participate in short duration, moderate to high intensity exercise. Although, low $\mathrm{CHO}$ diets have been found to have detrimental effects to performance during high intensity exercise. Conversely, higher supplementation of carbohydrate in the days/ weeks preceding a prolonged endurance event have resulted in improved performance time.

High fat diets in accordance with low $\mathrm{CHO}$ have also shown to improve performance when individuals are participating in moderate intensity endurance events ${ }^{10}$. This also elicited an increased fat oxidation and inhibited $\mathrm{CHO}$ oxidation likely due to the increased plasma FFA concentrations. The reasoning being that trained individuals who are adapted to high fat diets are able to transport, utilize, and oxidize fat at higher rates, which provides more energy during exercise than carbohydrate fuel. Ketogenic diets also known for decreasing body mass and body composition which was favorable for increased VO2max, because the less mass an individual needs to move allows for less required energy to working muscle, and thus results in an 
increased VO2max. Although, there have been inconsistent findings as to whether a diet higher in carbohydrate or fat would be most beneficial to performance. It seems that based off previous research those participating in a high $\mathrm{CHO}$ diet can perform for a longer amount of time until fatigue, and produce more mean power compared to those on a high fat ${ }^{10,14}$.

It is still unclear how dietary intake may affect performance of anaerobic athletes during increasing intensity aerobic exercise, due to lack of feasibility and research on this topic. Also, more research is needed to determine the duration of physiological adaptions at the muscular level as a result of changes in dietary composition. 


\section{References}

1. Romijn J.A., Coyle E.F., Sidossis L.S., Zhang X.J., Wolfe R.R. (1995). Relationship between fatty acid delivery and fatty acid oxidation during strenuous exercise. J Appl Physiol,79(6):1939-1945.

2. Romijn J.A., Coyle E.F., Sidossis L.S., et al. (1993). Regulation of endogenous fat and carbohydrate metabolism in relation to exercise intensity and duration. Am J Physiol.265(3 Pt 1):E380-391.

3. Jeukendrup A.E. (2003). High-carbohydrate versus high-fat diets in endurance sports. In. Vol 51: Schweizerische Zeitschrift fur;:17-23.

4. $\quad$ Katz A., Broberg S., Sahlin K., Wahren J. (1986). Leg glucose uptake during maximal dynamic exercise in humans. Am J Physiol. 251(1 Pt 1):E65-70.

5. Krogh A., Lindhard J. (1920). The Relative Value of Fat and Carbohydrate as Sources of Muscular Energy: With Appendices on the Correlation between Standard Metabolism and the Respiratory Quotient during Rest and Work. Biochem J.;14(3-4):290-363.

6. Hansen C.( 1939b). Arbeitsfahigkeit und Ernahrung.

7. Pitsiladis, Y. P., Maughan, R. J. (1999). The Effects Of Alterations In Dietary Carbohydrate Intake On The Performance Of High-Intensity Exercise In Trained Individuals. European Journal of Applied Physiology 79.5

8. Pitsiladis Y.P., Duignan C., Maughan R.J. (1998). Effects of alterations in dietary carbohydrate intake on running performance during a $10 \mathrm{~km}$ treadmill time trial. $\mathrm{Br} J$ Sports Med.;30(3):226-231.

9. Williams C., Brewer J., Walker M. (1992). The effect of a high carbohydrate diet on running performance during a 30-km treadmill time trial. Eur J Appl Physiol Occup Physiol.65(1):18-24.

10. Zajac A, Poprzecki S, Maszczyk A, Czuba M, Michalczyk M, Zydek G. (2014). The effects of a ketogenic diet on exercise metabolism and physical performance in off-road cyclists. Nutrients. 6(7):2493-2508.

11. Helge J.W., Wulff B., Kiens B. (1998). Impact of a fat-rich diet on endurance in man: role of the dietary period. Med Sci Sports Exerc. 30(3):456-461.

12. Langfort J., Pilis W., Zarzeczny R., Nazar K., Kaciuba-Uściłko H. (1996). Effect of lowcarbohydrate-ketogenic diet on metabolic and hormonal responses to graded exercise in men. J Physiol Pharmacol.47(2):361-371. 
13. Burke L.M., Hawley J.A., Angus D.J., et al. (2002). Adaptations to short-term high-fat diet persist during exercise despite high carbohydrate availability. Med Sci Sports Exerc.;34(1):83-91.

14. Muoio D.M., Leddy J.J., Horvath P.J., Awad A.B., Pendergast D.R. (1994). Effect of dietary fat on metabolic adjustments to maximal VO2 and endurance in runners. Med Sci Sports Exerc.;26(1):81-88.

15. Phinney S.D., Bistrian B.R., Evans W.J., Gervino E., Blackburn G.L. (1983). The human metabolic response to chronic ketosis without caloric restriction: preservation of submaximal exercise capability with reduced carbohydrate oxidation.

Metabolism.32(8):769-776.

16. Helge J.W., Richter E.A., Kiens B. (1996). Interaction of training and diet on metabolism and endurance during exercise in man. J Physiol. 492 ( Pt 1):293-306.

17. Carey A.L., Staudacher H.M., Cummings N.K., et al. (2001). Effects of fat adaptation and carbohydrate restoration on prolonged endurance exercise. $J$ Appl Physiol (1985).;91(1):115-122.

18. McArdle W.D., Katch F.I., Katch V.L. Exercise Physiology: Nutrition, Energy, and Human Performance. Eighth ed: Philadelphia : Wolters Kluwer Health/Lippincott Williams \& Wilkins,; 2015.

19. Simonsen J.C., Sherman W.M., Lamb D.R., Dernbach A.R., Doyle J.A., Strauss R. (1991). Dietary carbohydrate, muscle glycogen, and power output during rowing training. J Appl Physiol (1985).;70(4):1500-1505.

20. Sherman W.M., Costill D.L., Fink W.J., Miller J.M. (1981). Effect of exercise-diet manipulation on muscle glycogen and its subsequent utilization during performance. Int $J$ Sports Med:;2(2):114-118.

21. Patterson R., Potteiger J.A. (2011). A comparison of normal versus low dietary carbohydrate intake on substrate oxidation during and after moderate intensity exercise in women. Eur J Appl Physiol.;111(12):3143-3150.

22. Putman C.T., Spriet L.L., Hultman E., et al. (1993). Pyruvate dehydrogenase activity and acetyl group accumulation during exercise after different diets. Am J Physiol:;265(5 Pt 1):E752-760.

23. Gaskill S.E., Walker A.J., Sanchez O.A., Serfass R.C., Leon A.S. (2001). Validity and reliability of combining three methods to determine ventilatory threshold. Medicine \& Science in Sport \& Exercise.;33:1841-1848. 
24. Romijn J.A., Coyle E.F., Hibbert J., Wolfe R.R. (1992). Comparison of indirect calorimetry and a new breath $13 \mathrm{C} / 12 \mathrm{C}$ ratio method during strenuous exercise. Am J Physiol.;263(1 Pt 1):E64-71.

25. Coyle E.F. (1995). Substrate utilization during exercise in active people. Am J Clin Nutr.;61(4 Suppl):968S-979S.

26. Coyle E.F., Coggan A.R., Hemmert M.K., Ivy J.L. (1986). Muscle glycogen utilization during prolonged strenuous exercise when fed carbohydrate. J Appl Physiol (1985).;61(1):165-172.

27. Peters S.J., Leblanc P.J. (2004). Metabolic aspects of low carbohydrate diets and exercise. Nutr Metab (Lond).;1(1):7.

28. Manninen A.H. (2004). Metabolic effects of the very-low-carbohydrate diets: misunderstood "villains" of human metabolism. J Int Soc Sports Nutr.;1(2):7-11.

29. Jansson E., Kaijser L. (1982). Effect of diet on the utilization of blood-borne and intramuscular substrates during exercise in man. Acta Physiol Scand.;115(1):19-30.

30. Bergström J., Hultman E. (1966). Muscle glycogen synthesis after exercise: an enhancing factor localized to the muscle cells in man. Nature.;210(5033):309-310.

31. Frayn K.N. Metabolic Regulation: A Human Perspective. 3rd ed: Wiley-Blackwell; 2010.

32. Green H.J., Patla A.E. (1992). Maximal aerobic power: neuromuscular and metabolic considerations. Med Sci Sports Exerc.;24(1):38-46.

33. Stanley W.C., Connett R.J. (1991). Regulation of muscle carbohydrate metabolism during exercise. FASEB J.;5(8):2155-2159.

34. Coggan R.A., Mendenhall A.L. (1992). Effect of Diet on Substrate Metabolism During Exercise. In: Perspectives in Exercise Science:435-465.

35. Lemon P.W, Mullin J.P. (1980). Effect of initial muscle glycogen levels on protein catabolism during exercise. J Appl Physiol Respir Environ Exerc Physiol.;48(4):624-629. 